Original Research Article

\title{
Study of clinical efficacy, safety and tolerability of low cost branded generic antiepileptic drugs in children and adolescents
}

\author{
Neha Vijay Parekh ${ }^{1}$, Ruth Susan George ${ }^{1}$, Adhiraj Dharmadhikari ${ }^{1}$, Kavita Srivastava ${ }^{2}$, \\ Bijoy Kumar Panda ${ }^{1 *}$
}

\begin{abstract}
${ }^{1}$ Department of Clinical Pharmacy, Bharati Vidyapeeth (Deemed to be University), Poona College of Pharmacy, Pune, Maharashtra, India ${ }^{2}$ Department of Pediatrics, Bharati Hospital and Research Centre, Bharati Vidyapeeth (Deemed to be University), Pune, Maharashtra, India
\end{abstract}

Received: 07 June 2019

Revised: 29 June 2019

Accepted: 03 July 2019

*Correspondence to: Bijoy Kumar Panda, Email: bijoy.panda@ bharatividyapeeth.edu

Copyright: (C) the author(s), publisher and licensee Medip Academy. This is an openaccess article distributed under the terms of the Creative Commons Attribution NonCommercial License, which permits unrestricted noncommercial use, distribution, and reproduction in any medium, provided the original work is properly cited.

\begin{abstract}
Background: Generic substitution is preferred to reduce healthcare costs and improve patient adherence. The review of literature showed that physicians all around the world were not comfortable in prescribing generic medications due to the lack of evidence on their safety and efficacy.

Methods: A prospective study was conducted over a period of one year in Pune. The patients were categorized on their age and were assessed for the clinical effectiveness data (no. of breakthrough seizures and seizure free days) and safety data (no. of ADR episodes). The mean number of patients controlled and the frequency of adverse events at the $3^{\text {rd }}$ and $6^{\text {th }}$ month were calculated.

Results: Authors assessed 150 newly diagnosed pediatric epileptic patients who received anti-epileptic drug monotherapy for at least 6 months, out of which 46 $(30.66 \%)$ received Oxcarbazepine and $104(69.33 \%)$ received Sodium Valproate. At the end of 3 months of therapy $140(93.33 \%)$ patients were seizure free and $145(96.66 \%)$ patients were seizure free at the end of 6 months. Adverse effects were observed in $14(30.43)$ patients on oxcarbazepine and $26(25 \%)$ patients on sodium valproate. The most common adverse effect was weight gain in 34 (22.66\%) patients with both the AEDs.

Conclusions: Seizure control was achieved in majority of the patients. In addition to the seizure control, the frequency of adverse effects was few and tolerable by the patients when prescribed with low cost branded generics.
\end{abstract}

Keywords: Antiepileptic drugs, Branded generic, Epilepsy, Oxcarbazepine, Sodium valproate

\section{INTRODUCTION}

Epilepsy is a neurological disorder, which may be severe, life threatening and disabling, to ones that are much more benign. ${ }^{1}$ The prevalence of epilepsy is 5 per 1000 in India. However, the prevalence is slightly high in the Indian rural area. Epilepsy is more commonly seen in the first years of life, early childhood and after adolescent. ${ }^{2}$ The branded versus generic debate is ongoing one, with various stakeholders actively involved in it. A branded generic is a drug that is bioequivalent to the original (innovator) brand but marketed under another company's brand name. ${ }^{3}$ A systematic review and meta-analysis of trials comparing seizure outcomes from use of branded and generic antiepileptic drugs (AEDs) showed no association between loss of seizure control and generic substitution. In the 
absence of better data, there is little evidenced-based rationale to challenge the implementation of generic substitution for AEDs in most cases. ${ }^{4}$ On the contrary, it is not the prescribing of generic AEDs that appears to be the problem; it is switching between two brands. Once a critical effective dose with an anti-epileptic drug is achieved, swapping to a drug with a slightly different formulation can change the critical dose needed, and control of seizures may be lost. ${ }^{5}$ Low cost branded generics is preferred to reduce the healthcare costs and improve patient adherence. ${ }^{6}$ The review of literature showed that physicians all around the world were not comfortable in prescribing generic medications due to the lack of evidence on their safety and efficacy. To provide evidence for the same, low cost branded generic antiepileptic drugs were selected for this study.

\section{METHODS}

\section{Study design}

A prospective study was carried out in a tertiary care teaching hospital, Pune, India from August 2017 to August 2018 under normal clinical practice. Low cost branded generics like Oxetol ${ }^{\circledR}$ (Oxcarbazepine) and Encorate Chrono $^{\circledR}$ (Sodium Valproate) manufactured by Sun Pharma Laboratories Ltd. were selected. The branded counterpart Trioptal ${ }^{\circledR} 150 \mathrm{mg}$ and $300 \mathrm{mg}$ manufactured by Novartis India Ltd. was available for Rs. 80 and Rs. 149 per 10 tablets respectively. Whereas, Tab. Oxetol ${ }^{\circledR} 150 \mathrm{mg}$ and 300mg was available for Rs. 57 and Rs. 90 per 10 tablets respectively. Similarly, the branded counterpart, Valparin $\mathrm{CR}^{\circledR}$ 200mg and 300mg (sodium valproate ) manufactured by Sanofi India is available for Rs. 59.95 and Rs. 60.2 per 10 tablets respectively. Whereas, Tab. Encorate Chrono ${ }^{\circledR} 200 \mathrm{mg}$ and $300 \mathrm{mg}$ is available for Rs. 36.55 and Rs. 41.60 per 10 tablets respectively during the study period. This is approximately $30-40 \%$ cheaper than its branded formulation. This difference in the price range will prove extremely beneficial especially to the lowincome population as epilepsy is a long-term treatment. These branded AEDs were preferred by most of the paediatricians for treating epilepsy.

These low cost branded generics of oxcarbazepine and sodium valproate were preferred among other generic brands because of availability of desired strength and formulations by these manufacturers for paediatric population. Ethical approval was obtained from the Institutional Ethics committee. Prescriptions of the IPD and OPD patients were scrutinized for mono-therapy with a single AED i.e. oxcarbazepine and sodium valproate.

\section{Inclusion criteria}

All newly diagnosed epileptic patients who were prescribed with monotherapy and with no co-morbidities were included in the study.

\section{Exclusion criteria}

Patients with West syndrome, epileptic encephalopathy, neuro degenerative condition and known sensitivity to oxcarbazepine and sodium valproate were excluded from the study.

The paediatric epileptic patients were further subdivided into the following age groups: 1-12 years (Children) and 12-18 years (Adolescents) as per the WHO classification. ${ }^{7}$ The clinical efficacy and safety profile of low cost branded generic AEDs were evaluated. Selected patients were followed up at the 3rd and 6th month from the start of the therapy. Follow up was obtained on OPD visits by one to one communication with the patients and those who failed to return to the hospital for follow up visits were contacted over telephone.

\section{Efficacy assessment}

The primary outcome parameters for evaluation of clinical efficacy of low cost branded generic AEDs were number of breakthrough seizures, initial seizure free days and compliance with the drug therapy or any change in the drug therapy. A breakthrough seizure is a sudden unaccepted seizure that may result from missing a dose, taking less than the prescribed dose, withdrawal from excessive use of alcohol or illness. ${ }^{8}$ Seizure free days are the number of days before the occurrence of first seizure after starting antiepileptic therapy.

\section{Safety and tolerability assessment}

Specific adverse events of the two drugs were selected with the help of package labels and drug reference database (Micromedex) to evaluate the safety. These were obtained at the $3^{\text {rd }}$ and $6^{\text {th }}$ month from the start of therapy. ${ }^{9-11}$ Tolerability was assessed based on the number of patients that withdrew from the study because of recurrence of seizures and adverse effects. The change in antiepileptic therapy in patients who experienced recurrent episodes of seizures or major adverse events were excluded from the study.

\section{Statistical analyses}

The above data was documented and captured in Microsoft Excel 2007 for further analysis. Discrete data of gender, age, number of patients controlled and frequency of adverse events at the third and sixth month were expressed as numbers and percentages. Measurement data such as mean dose and mean seizure free days were expressed along with standard deviation. The results were compared with the world literature for branded AEDs in children.

\section{RESULTS}

\section{Demographics}

Out of 156 patients that were initially included in this study, 6 patients were excluded from the study due to change in the drug or associated co-morbidities. The data 
of 150 newly diagnosed pediatric epileptic patients who received anti-epileptic drug monotherapy for at least 6 months were analyzed. Authors demonstrated the outcome of epilepsy in relation to age, gender, no. of seizure free days and breakthrough seizures, occurrence of ADR and mean dose requirements. Out of the 150 patients, 46 $(30.66 \%)$ received Oxetol $^{\circledR}$ (Oxcarbazepine) and 104 (69.33\%) received Encorate Chrono ${ }^{\circledR}$ (Sodium Valproate) monotherapy. The percentage of males and females receiving Oxetol ${ }^{\circledR}$ (Oxcarbazepine) monotherapy was equal whereas the percentage of males was higher than females in patients receiving Encorate Chrono ${ }^{\circledR}$ (Sodium Valproate) monotherapy. The mean weight of the patients was $25.81 \pm 10.33 \mathrm{~kg}$ and $24.56 \pm 14.10 \mathrm{~kg}$ on Oxetol $^{\circledR}$ (Oxcarbazepine) and Encorate Chrono $^{\circledR}$ (Sodium Valproate) respectively (Table 1).

Table 1: Demographic characteristics of patients on Oxetol® (Oxcarbazepine) and Encorate Chrono® (Sodium Valproate).

\begin{tabular}{|c|c|c|c|}
\hline \multicolumn{2}{|c|}{ Parameter } & Oxetol $^{\circledR}($ Oxcarbazepine $)(\mathrm{N}=46)$ & Encorate Chrono ${ }^{\circledR}$ (Sodium Valproate) $(\mathbf{N}=104)$ \\
\hline \multirow{2}{*}{ Gender } & Male & $23(50 \%)$ & $74(71.15 \%)$ \\
\hline & Female & $23(50 \%)$ & $30(28.84 \%)$ \\
\hline \multirow{2}{*}{ Age } & $1-12$ years & $36(78.26 \%)$ & $84(80.76 \%)$ \\
\hline & $12-18$ years & $10(21.73 \%)$ & $20(19.23 \%)$ \\
\hline \multicolumn{2}{|c|}{ Mean weight in $\mathrm{kg} \pm \mathrm{SD}$} & $25.81 \pm 10.33$ & $24.56 \pm 14.10$ \\
\hline
\end{tabular}

Table 2: Distribution of patients, mean weight and mean dose of Oxetol ${ }^{\circledR}$ (Oxcarbazepine)and Encorate Chrono ${ }^{\circ}$ (Sodium Valproate) prescribed according to the type of epilepsy.

\begin{tabular}{|lllllll|}
\hline $\begin{array}{l}\text { Type of } \\
\text { epilepsy }\end{array}$ & $\begin{array}{l}\text { Oxetol }^{\circledR} \\
(\mathbf{N}=46)\end{array}$ & $\begin{array}{l}\text { Mean weight } \\
\text { in kg } \pm \text { SD }\end{array}$ & $\begin{array}{l}\text { Mean dose in } \\
\mathbf{m g} / \mathbf{k g} / \text { day } \pm \text { SD }\end{array}$ & $\begin{array}{l}\text { Encorate } \\
(\mathbf{N}=104)\end{array}$ & $\begin{array}{l}\text { Mean weight } \\
\text { in kg } \pm \text { SD }\end{array}$ & $\begin{array}{l}\text { Mean dose in } \\
\text { mg/kg/day } \pm \text { SD }\end{array}$ \\
\hline Partial (N=64) & $20(43.47 \%)$ & $30.07 \pm 11.96$ & $17.17 \pm 7.83$ & $44(42.30 \%)$ & $23.18 \pm 7.70$ & $14.67 \pm 6.79$ \\
\hline $\begin{array}{l}\text { Generalised } \\
(\mathrm{N}=80)\end{array}$ & $24(52.17 \%)$ & $22.48 \pm 8.61$ & $16.44 \pm 4.98$ & $56(53.84 \%)$ & $25.97 \pm 17.97$ & $13.97 \pm 6.30$ \\
\hline Unclassified & $2(4.34 \%)$ & - & - & $4(3.84 \%)$ & $20 \pm 6.22$ & $15.76 \pm 4.90$ \\
\hline
\end{tabular}

Table 3: Seizure free days (mean) and number of seizure free patients receiving Oxetol $($ Oxcarbazepine) and Encorate Chrono® (Sodium Valproate).

\begin{tabular}{|lll|}
\hline Drug & Mean no. of seizure free days \pm SD & Seizure free patients at the end of $\mathbf{6}$ months, N (\%) \\
\hline $\begin{array}{l}\text { Oxetol }{ }^{\circledR} \\
\text { (Oxcarbazepine) }^{\circledR}\end{array}$ & $169.7 \pm 30$ & $42(91.30 \%)$ \\
\hline $\begin{array}{l}\text { Encorate Chrono } \\
\text { (Sodium Valproate) }\end{array}$ & $172 \pm 32$ & $102(98.07 \%)$ \\
\hline
\end{tabular}

The most common type of epilepsy with both the drugs was found to be generalized epilepsy in $80(53.33 \%)$ patients followed by partial epilepsy in $64(42.66 \%)$ patients. The mean doses of both the drugs on which the patients were stabilized for different types of epilepsy are shown in Table 2. In total, $140(93.33 \%)$ patients were seizure free at 3 months and $145(96.66 \%)$ patients were seizure free at 6 months. No. of breakthrough seizures were observed in $10(6.66 \%)$ patients at 3 months and 5 $(3.33 \%)$ at 6 months with both the drugs (Table 3 ).

\section{Adverse effect profile of Oxetol ${ }^{\circledR}$ (Oxcarbazepine) and Encorate Chrono ${ }^{\circledR}$ (Sodium Valproate)}

Out of 46 patients who received Oxetol ${ }^{\circledR}$ (Oxcarbazepine), $14(30.43 \%)$ patients developed adverse effects. In case of
Encorate Chrono ${ }^{\circledR}$ (Sodium Valproate), 26 (25\%) patients developed adverse effects. The most common adverse effect with both the drugs was found to be weight gain in $34(22.66 \%)$ patients. The average increase in the weight was found to be $9 \%$ (6 months) with both the drugs. The second most commonly found adverse effect was headache, which was experienced by $4(2.66 \%)$ patients with both drugs which was well tolerated. Enuresis was observed in $2(1.92 \%)$ patients receiving Encorate Chrono $^{\circledR}$ (Sodium Valproate). Hence, the overall rates of adverse effects with Oxetol ${ }^{\circledR}$ (Oxcarbazepine) was $30.43 \%$ and with Encorate Chrono ${ }^{\circledR}$ (Sodium Valproate) was $25 \%$ (Fig 1). All the patients included in the study were tolerable to the treatment given as none of them withdrew from the study due to seizure recurrence or adverse effects. 


\section{DISCUSSION}

This study was designed to investigate the efficacy and adverse effect profile of low cost branded generic AEDs in newly diagnosed paediatric epileptic patients. Out of the 150 patients included in the study, $64(42.66 \%)$ patients had partial epilepsy, $80(62.85 \%)$ patients had generalized epilepsy and $2(1.33 \%)$ patients had unclassified epilepsy. Patients were treated with Oxetol ${ }^{\circledR}$ (Oxcarbazepine) and Encorate Chrono ${ }^{\circledR}$ (Sodium Valproate) were chosen due to their low cost and availability of desired formulations as compared to other branded generic formulations available in the local market.

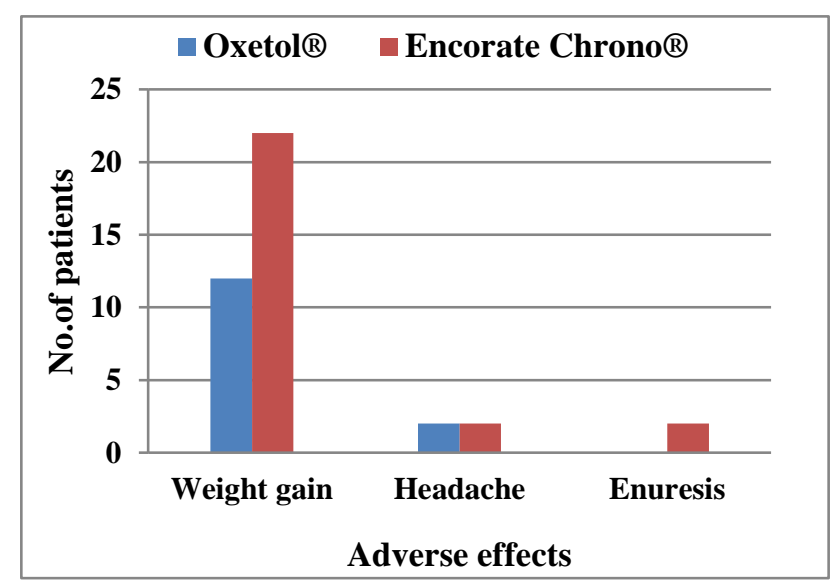

\section{Figure 1: Adverse effects due to Oxetol ${ }^{\circledR}$ (Oxcarbazepine)and Encorate Chrono® (Sodium Valproate) in the study population.}

The fundamental goal of anti-epileptic therapy is to prevent seizures without causing side effects from the medications. The AED chosen for the initial therapy should be one that is highly effective for the particular seizure type or syndrome as well as safe and well tolerable.

In this study, $96.6 \%$ percent of pediatric epileptic patients reached a state of seizure freedom at 6 months which was in accordance with previous studies conducted by Mikiko Yamada and Timothy E. Welty. ${ }^{12}$ This study revealed no significant difference in seizure frequency between brand and generic AEDs. Aaron S. Kesselheim et al..$^{5}$ conducted a study that evaluated the comparison of brand and generic AEDs. In these studies, the aggregate odds ratio was 1.0 for the former and 1.1 for the latter, indicating no difference in the odds of uncontrolled seizure for patients on generic medications compared to patients on brandname medications. The majority of seizure free patients required only a moderate daily dose $(10-20 \mathrm{mg} / \mathrm{kg} / \mathrm{day})$ of the AEDs. Doses were only increased in patients who experienced uncontrolled seizures and had an occurrence of ADR. 5 patients on Oxetol ${ }^{\circledR}$ (Oxcarbazepine) and 8 patients on Encorate Chrono ${ }^{\circledR}$ (Sodium Valproate) received increased doses of the respective drugs due to seizure reoccurrence or weight gain.
Generic prescribing is preferred to reduce the healthcare costs. However, a debate persists regarding the safety and efficacy of generics for treatment of epilepsy. In a multinational survey of patients in $2005,23 \%$ believed that generics are linked to breakthrough seizures, while $58 \%$ were uncomfortable with using a generic to treat their epilepsy. ${ }^{13} \mathrm{In}$ a survey of physicians, $88 \%$ reported being concerned about an increase in breakthrough seizures from generics. Muhammad Atif et al. ${ }^{14}$ in their review of literature reported an increase in the no. of breakthrough seizures and adverse effects with generic Oxcarbazepine and Sodium Valproate. In response to the debate that persists regarding generic prescribing, this study reported a $91.30 \%$ and $98.07 \%$ improvement in seizure control with Oxcarbazepine and Sodium Valproate respectively. The mean number of seizure free days in patients on Oxetol ${ }^{\circledR}$ (Oxcarbazepine) was found to be $169.7 \pm 30$ days whereas, mean number of seizure free days in patients on Encorate Chrono ${ }^{\circledR}$ (Sodium Valproate) was found to be $172.2 \pm 32$ days.

This study concerns with branded generic prescribing of AEDs in newly diagnosed pediatric epilepsy patients resulting in a minimization of ADR episodes. This can be attributed to the inclusion of patients who are on a single AED and who are not switched between different branded generic formulations or from branded to branded generic AEDs. In contrast, previous studies focusing on the switch from brand to generic AEDs reported an increase in the adverse effect profile resulting from the switch. In a survey conducted by Wilner A. ${ }^{6}$ out of 196 neurologists, 163 reported increased side effects in their patients after a switch from a brand name to generic AED. Concurrently, in a study conducted by Rahman $\mathrm{M}$ et al. ${ }^{15}$ comparing adverse event (AE) reporting rates for brand vs. authorized generic (AG) vs. generic AEDs, it was found that the brand reporting rates of Oxcarbazepine $(66.6 \%)$ were surprisingly higher than its generic form $(32 \%)$.

Once a critical effective dose to control the epilepsy is achieved with one drug, swapping to a drug with a slightly different formulation can change the critical dose needed, and control of seizures may be lost. According to NICE (National Institute for Health and Care Excellence) guidelines, when patients are maintained on the lowest dose of AED treatment that controls their seizure, a switch between different manufacturers of an AED is not recommended. ${ }^{16}$

A switch is only initiated if a person has an occurrence of breakthrough seizures or if the physician suggests a change in the treatment based on his experience. MHRA (Medicines and Healthcare products Regulatory Agency) guideline states, that in case of Oxcarbazepine and Sodium Valproate (Category 2 drugs), the need for continued supply of a particular manufacturer's product should be based on clinical judgment and consultation with patient and caregiver. ${ }^{17}$ This should be done by taking into account certain factors such as seizure frequency and treatment history. As a result, this study involves branded generic prescribing of AEDs in newly diagnosed epilepsy, 
hence overcoming the problems related with generic substitution.

Package labels of Oxcarbazepine and Sodium Valproate and drug reference database such as Micromedex stated common adverse events related to Oxcarbazepine were weight gain, gastrointestinal problems and headache and those related to Sodium Valproate were dizziness, headache and somnolence. In the study conducted by Rahman $\mathrm{M}$ et al. ${ }^{9-11,15}$ the adverse event reported for generic Oxcarbazepine were severe dermatologic reactions, angioedema and hyponatremia. In contrast, this study showed that out of 46 patients receiving Oxcarbazepine and 104 patients receiving Sodium Valproate, 12 and 22 patients experienced weight gain respectively. Headache was experienced by 2 patient each receiving Oxcarbazepine and Sodium Valproate whereas enuresis was seen only with Sodium Valproate. Hence, the overall rate of adverse effects with Oxcarbazepine $(30.43 \%)$ was more than that with Sodium Valproate $(25 \%)$. No patients withdrew from the study because of the adverse events as all the adverse events experienced were mild and tolerable.

The limitations of this study include a small sample size, short-term evaluations and physicians prescribing preference of brand over generic AEDs. Moreover, majority of the world literature focuses on generic AED substitution leading to an insufficient data regarding the safety and effectiveness of generic versus brand AED monotherapy.

In a study conducted by Naik N. ${ }^{18} 70 \%$ of pediatric epileptic patients treated with Trioptal ${ }^{\circledR}$ (Oxcarbazepine) were seizure free at the end of 24 weeks and had an adverse event rate of $8.9 \%$. Similarly, in a prospective study by Belousova et al, complete reduction of seizures was achieved in $59.4 \%$ of pediatrics patients and adverse effects were observed in $11.2 \%$ of patients treated with Trioptal ${ }^{\circledR}$ (Oxcarbazepine) ${ }^{19}$ Whereas, this study reported that $91.30 \%$ of patients on Oxetol ${ }^{\circledR}$ (Oxcarbazepine) were seizure free at the end of 6 months and the adverse event rate was $33.33 \%$. Weight gain was the most common adverse event being recorded in $27.77 \%$ of subjects followed by headache in $5.55 \%$ of the subjects.

In a study conducted by Richens A. et al. ${ }^{20} 65 \%$ of adult epileptic patients treated with Sodium Valproate showed signs of toxicity like drowsiness, ataxia and nausea which were mild and transient and the frequency of seizure episodes were reduced to $35-57 \%$. This study reported that $94.23 \%$ of patients were seizure free with Encorate Chrono $^{\circledR}$ (Sodium Valproate) at the end of 6 months. The overall rate of adverse event was $23.07 \%$ including weight gain, headache and enuresis.

Since, the incidence and prevalence of epilepsy in children is higher in rural population, low cost branded generic prescribing will benefit this population due to its cost effectiveness and in turn improve the patient compliance. Furthermore, it will contribute in building confidence among physicians concerning prescription of low cost branded generic over brand anti-epileptic drugs. Seizure control was achieved in majority of the patients. In addition to the seizure control, the frequency of ADR episodes was few and tolerable by the patients. These low cost branded generics were found to be efficacious, safe and tolerable.

\section{ACKNOWLEDGEMENTS}

Authors would like to thanks to college staff members for their guidance and timely support. Authors wish to express thanks to the Department of Pediatrics, Bharati Hospital and Research Centre, Pune, for helping us in the completion of the study.

Funding: No funding sources

Conflict of interest: None declared

Ethical approval: The study was approved by the Institutional Ethics Committee

\section{REFERENCES}

1. Ninds.nih.gov. (2019). Epilepsies Information Page | National Institute of Neurological Disorders and Stroke. Available at: www.ninds.nih.gov/Disorders/AllDisorders/Epilepsy-Information-Page. Accessed 11 Mar 2019.

2. Shakirullah, Niaz A., Aslam K, Muhammad N. The Prevalence, Incidence and Etiology of Epilepsy. Int $\mathbf{J}$ Clin Exp Neurol. 2014 Dec 28;2(2):29-39.

3. Gilbert T, Ural A, Lopez M. Five Branded Generics Strategies to Master for Global Pharmaceuticals in Emerging Markets. Accenture Life Sciences, Dublin. 2012.

4. Kesselheim AS, Stedman MR, Bubrick EJ, Gagne JJ, Misono AS, Lee JL, et al. Seizure outcomes following the use of generic versus brand-name antiepileptic drugs. Drugs. 2010 Mar 1;70(5):605-21.

5. Virtual Medical Centre (2009). Generic Antiepileptic Drugs and Branded Antiepileptic Drugs. Available at: https://www.myvmc.com/treatments/genericantiepileptic-drugs-and-branded-antiepileptic-drugs/. (Accessed 11 April 2019).

6. Wilner AN. Therapeutic equivalency of generic antiepileptic drugs: results of a survey. Epil Behav. 2004 Dec 1;5(6):995-8.

7. Knoppert D, Reed M, Benavides S, Totton J, Hoff D, Moffett B, et al. Paediatric age categories to be used in differentiating between listing on a model essential medicines list for children. Word Health Organization position paper. 2007;1(5).

8. Epilepsy Foundation of Greater Chicago. Breakthrough Seizures. Available at: https://epilepsychicago.org/epilepsy/treatment/breakt hrough-seizures/. Accessed 19 April 2019.

9. FDA. Oxcarbazepine. https://www.accessdata.fda.gov/drugsatfda_docs/labe 1/2007/077795s000lbl.pdf. Accessed 29 April 2018. 
10. FDA. Valproic Acid. Available at: https://www.accessdata.fda.gov/drugsatfda_docs/labe 1/2009/022152s002lbl.pdf. Accessed 29 April 2018.

11. IBM Micromedex TM. https://www.micromedexsolutions.com/home/dispatc h/ssl/true. (Accessed 24 February 2019).

12. Yamada M, Welty TE. Generic substitution of antiepileptic drugs: a systematic review of prospective and retrospective studies. Ann Pharmacother. 2011 Nov 25; 45(11):1406-15.

13. Shaw SJ, Hartman AL. The controversy over generic antiepileptic drugs. J Pediatr Pharmacol Therap. 2010 Apr;15(2):81-93.

14. Atif M, Azeem M, Sarwar MR. Potential problems and recommendations regarding substitution of generic antiepileptic drugs: a systematic review of literature. SpringerPlus. 2016 Dec 1;5(1):182.

15. Rahman MM, Alatawi Y, Cheng N, Qian J, Plotkina $\mathrm{AV}$, Peissig PL, et al. Comparison of brand versus generic antiepileptic drug adverse event reporting rates in the US Food and Drug Administration Adverse Event Reporting System (FAERS). Epilepsy research. 2017 Sep 1;135:71-8.

16. National Institute for Health Clinical Excellence (NICE). Epilepsies: Diagnosis and Management. Available https://www.nice.org.uk/guidance/cg137. Accessed 26 February 2019.

17. Medicines and Healthcare products Regulatory Agency GOV.UK. Gov.uk. 2018 Available at: https://www.epilepsysociety.org.uk/mhra-guidance-antiepileptic-drugs\#.WuWmOe-FPIU. Accessed 29 April 2018.

18. Naik N, Gawai A. Efficacy, safety and tolerability of Trioptal®(oxcarbazepine) in children and adolescents with newly diagnosed partial seizures or generalized tonic-clonic seizures: results of a 6 months, prospective, open-label, multicentre, non-comparative, observational post-marketing surveillance study. Ind Med Gazette. 2012;146:324-30.

19. Belousova ED, Mukhin K, Ermolenko NA, Guzeva VI, Tysiachina MD, Mironov MB, et al. Efficacy and safety of the monotherapy with trileptal (oxcarbazepine) in children and adolescents. Zhurnal Nevrologii i Psikhiatrii Imeni SS Korsakova. 2010;110(5 Pt 1):45-50.

20. Richens A, Ahmad S. Controlled trial of sodium valproate in severe epilepsy. Br Med J. 1975 Nov 1;4(5991):255-6.

Cite this article as: Parekh NV, George RS, Dharmadhikari A, Srivastava K, Panda BK. Study of clinical efficacy, safety and tolerability of low cost branded generic antiepileptic drugs in children and adolescents. Int J Basic Clin Pharmacol 2019;8:172833. 